\title{
4H-SiC $\{0001\}$ 近傍面へのホモエピタキシャル成長 ${ }^{\dagger}$ 中 村 俊 - * 木 本 恒 暢 ${ }^{*}$ 松波弘之海 Homoepitaxial Growth on 4H-SiC $\{0001\}$-Vicinal Faces
}

\author{
by \\ Shun-ichi NaKamura ${ }^{*}$, Tsunenobu Kimoto ${ }^{*}$ and Hiroyuki Matsunami ${ }^{* *}$
}

\begin{abstract}
Homoepitaxial growth on $4 \mathrm{H}-\mathrm{SiC}\{0001\}$-vicinal faces by chemical vapor deposition (CVD) operating at $1500^{\circ} \mathrm{C}$ is investigated. Homoepitaxy is successful for both $0.2^{\circ}$-off $4 \mathrm{H}-\mathrm{SiC}(0001)_{\mathrm{si}}$ and $0.7^{\circ}$-off $4 \mathrm{H}-\mathrm{SiC}(000 \overline{1})_{\mathrm{C}}$ faces, as well as a $3.5^{\circ}$-off $(0001)_{\mathrm{Si}}$ face. In the case of $(0001)_{\mathrm{Si}}$ faces, reduction of $\mathrm{C} / \mathrm{Si}$ ratio during $\mathrm{CVD}$ growth and wafer re-polishing are effective to suppress formation of major surface defects like carrots and extending triangles, which, however, were not completely eliminated probably due to polishing damages remaining near the wafer surfaces. For $(000 \overline{1})_{C}$ faces, the density of major surface defects, namely pits and extending triangles, decreases with increasing thickness of pre-growth thermal oxide up to $0.4 \sim 0.5 \mu \mathrm{m}$. Thus, for $(000 \overline{1})_{\mathrm{C}}$ faces, proper thermal oxidation is effective to remove surface damages induced during wafer preparation that might cause the major surface defects.
\end{abstract}

Key words : Silicon carbide (SiC), \{0001\}-vicinal face, Homoepitaxial growth, Chemical vapor deposition

\section{1 緒言}

半導体 $\mathrm{SiC}$ は, 広禁制帯幅, 高絶縁破壞電界, 高熱伝 導度といった優れた物性を有するため, 次世代パワーデ バイス用材料の最有力候補に挙げられている. ${ }^{1)}{ }^{2)} \mathrm{SiC}$ は 化学的には同一組成でありながら積層方向 $(<0001>$ 方 向）の積み重なり順序が異なるポリタイプ現象を示すた め, とりわけ\{0001\} 面上へのホモエピタキシャル成長に おいては異種ポリタイプの混入が問題であった. 1987 年, 筆者らは $\{0001\}$ 面から数度のオフを導入するステップ制 御エピタキシーを提案し (3)この技術を用いた $\mathrm{SiC}$ 電子デバ イスの実用化が始まりつつある. 現在, 市販の $4 \mathrm{H}-\mathrm{SiC}$ $\{0001\}$ 面は 8 度オフが標準となっている. しかし, 実用 化に際してウエー八径の拡大が要求されるようになった現 在, インゴット長の制限が強い $\mathrm{SiC} に$ にいては, 低オフ 角基板, 理想的にはほぼオフ無し基板へのホモエピタキ シャル成長の実現が緊急の課題となっている.

$\mathrm{SiC}\{0001\}$ 近傍面へのホモエピタキシャル成長の実現 可能性は，古くは 1991 年から報告がある.4)しかし，再現 性が芝しかったことから, 長らく省みられなかった。数 年前，筆者らは $\mathrm{SiC}$ 表面を精密に制御することによって, $6 \mathrm{H}-\mathrm{SiC}(0001)_{\mathrm{Si}}$ 面 0.2 度オフ基板上に $1 \mathrm{~cm} \times 1 \mathrm{~cm}$ 以上 にもわたって表面欠陥を含まないホモエピタキシャル成 長に成功した . ${ }^{5} 4 \mathrm{H}-\mathrm{SiC}(0001)_{\mathrm{Si}}$ 面に対しては，一部の $200 \mu \mathrm{m}$ 角メサ上でのホモエピタキシャル成長の報告例 6) があるものの, 通常の平面基板上へのホモエピタキシャ ル成長についてはこれまで報告されていない.

$\{0001\}$ 近傍面へのホモエピタキシャル成長において， 異種ポリタイプ, 特に $3 \mathrm{C}-\mathrm{SiC}$ が混入する原因として, か つては気相化学成長 (CVD) に打ける反応種の拡散距離7)
や外来の不純物8などが提案されていたが，筆者らは基 板作製時に導入される表面ダメージが表面欠陥，ひいて は 3C-SiC 混入の原因となると考えている.4), 5)オフ角が小 さいほど，表面ダメージの影響を受けやすいと考えてい る。しかし, $\mathrm{SiC}$ は極めて硬いため表面ダメージの制御が 難しく, 半導体級単結晶 $\mathrm{SiC}$ の表面加工と表面ダメージ に関する研究は少ない，一方で，本研究で問題にしてい る表面欠陥の中にはオフ角の正弦に反比例して拡大する ものもあるので，低オフ角化に伴い表面欠陥の全表面に 対して占める割合が急激に増加する。実用上は表面欠陥 密度を可能な限り低減する必要がある。

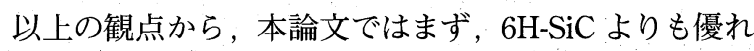
た物性を有し，実用上重要な $4 \mathrm{H}-\mathrm{SiC}(0001)_{\mathrm{Si}}$ 面に対し て，オフ角を 3.5 度， 0.2 度と小さくした場合の表面欠陥 の挙動について述べる。 そこで明らかになるように，基 板の表面加工（研磨）が表面欠陥密度に大きな影響を与 える。しかし，機械的あるいは機械化学的な研磨が $\mathrm{SiC}$ 表面に与えるダメージが明らかでない現在，表面欠陥を 発生させるようなダメージのない $(0001)_{\mathrm{Si}}$ 面を作製する のは容易ではない。

そこで本論文の後半では， $(000 \overline{1}) \mathrm{C}$ 面に注目した。 $(000 \overline{1})_{\mathrm{C}}$ 面は, $(0001)_{\mathrm{Si}}$ 面に比べて表面平坦性に優れてお り ${ }^{9}$ )また近年, MOS 界面特性に優孔るという報告 ${ }^{10)} も$ あ る.しかし，CVD 成長に打いて残留窑素ドナ一の取り込 み量が多いなど実用に際して問題があったため, 半導体 材料の分野ではこれまであまり深く追求されてこなかっ た、オフ角を小さくした場合の挙動についても，詳しく は報告されていない．この $(000 \overline{1})_{\mathrm{C}}$ 面は熱酸化速度が大 きい11), 12)ため, 長時間の熱酸化により比較的容易に最 表面を除去することができるという特徴がある. 


\section{$2(0001) \mathrm{Si}$ 近傍面へのホモエピタキシャル成長}

\section{$2 \cdot 1$ 実験}

本章の奏験には，Cree 社製 8 度オフおよび 3.5 度オフ $4 \mathrm{H}-\mathrm{SiC}(0001)_{\mathrm{Si}}$ 面，ならびに Sterling 社製 0.2 度オフ $4 \mathrm{H}-\mathrm{SiC}(0001)_{\mathrm{Si}}$ 面を基板として用いた。一部の基板は, NOVASiC 社による再研磨を行った。原子間力顛微鏡 (AFM) により基板表面を観察すると, Cree 社製基板に は深さ数 nm の研磨傷（溝）が無数に見られるのに刘し， NOVASiC 社により再研磨を行ったものには，研磨傷は 見られず，原子レベルで平坦であって，1 分子層高さのス テップが見られるほどである. Sterling 社製基板は, AFM で見る限りは NOVASiC 社により再研磨を行ったのとほ ほ同等の表面である。

エピタキシャル成長には，常圧横型コールドウォール CVD 成長装置 ${ }^{13)}$ を用いた。キャリアガスは $\mathrm{H}_{2}$ (流量 $3 \mathrm{~s} \mathrm{sm}$ ) であり，原料ガスは $\mathrm{SiH}_{4}$ （流量 $0.50 \mathrm{sccm}$ ）上 $\mathrm{C}_{3} \mathrm{H}_{8}$ （流 量 $0.26 \sim 1.00 \mathrm{sccm}, \mathrm{C} / \mathrm{Si}$ 比 1.6 - 6) である. 従来, $\mathrm{C} / \mathrm{Si}$ 比は 2 以上の条件を用いていたが，本研究では新た にC/Si 比 1.6 の条件を試みた。成長温度は $1500{ }^{\circ} \mathrm{C}$ あ゙あ り，成長時間は 1 ～時間である。これらの条件におい て，成長速度は $\mathrm{C}_{3} \mathrm{H}_{8}$ 流量 ${ }^{14)}$ 抢よび基板のオフ角によら ず, $3.5 \mu \mathrm{m} / \mathrm{h}$ 程度である。(0001) $\mathrm{Si}$ 近傍面へホモエピタ キシャル成長を行う場合，成長プロセスに特に注意が必 要であるが，こ机については既に筆者らが報告した通り である。年なおち，成長直前に $1300{ }^{\circ} \mathrm{C}$ での $\mathrm{HCl}(0.3 \%$ in $\mathrm{H}_{2}$ ）ガスエッチング 15)を行って基板表面の研磨ダメージ

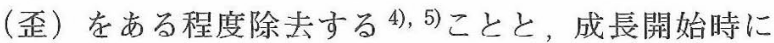
$\mathrm{SiH}_{4}$ 流量を減らす16)ことである。

\section{$2 \cdot 2$ 結果と討論}

Fig. 1 に, 3.5 度および 0.2 度オフ $4 \mathrm{H}-\mathrm{SiC}(0001)_{\mathrm{Si}}$ 面 成長層の典型的な表面モフォロジーを示す．CVD 成長時 の C/Si 比は 1.6 であり，成長膜厚は約 $5 \mu \mathrm{m}$ である。い ずれのオフ角に打いても全体としてはホモエピタキシャ ル成長が実現して扔り，1mm x $1 \mathrm{~mm}$ 以上にわたって平 坦な領域が得られている。ここに，ホモエピタキシャル 成長であることは，CVD 成長により $4 \mathrm{H}-\mathrm{SiC}$ の結晶構造 を反映した 4 分子層高さのステップが Fig. 2 に示すよう に表面に形成される ${ }^{17)}$ のを, AFM を用いて確認するこ とで決定した。Fig. 1 には CVD 成長条件等を最適化し た場合の表面モフォロジーを示しているが，いずれの成 長層にも $150 \sim 200 \mathrm{~cm}^{-2}$ の表面欠陥が見られる。3.5 度 オフの場合はオフの下流に向かって直線状に伸びるいわ ゆる carrot 欠陷が中心である（8度オフの場合も同様） が， 0.2 度オフの場合にはそれに垂直方向にも広がる三 角形状欠陷 (extending triangles) のみが見られる。これ らの表面欠陥は成長膜厚增大とともに拡大寸る*1ことが 知られているが，才フ角が極端に小さい 0.2 度オフの場 合には，成長膜厚が約 $5 \mu \mathrm{m}$ であっても表面欠陷が 700 $\mu \mathrm{m}$ にも渡って広がっている。したがって，0.2 度オフの
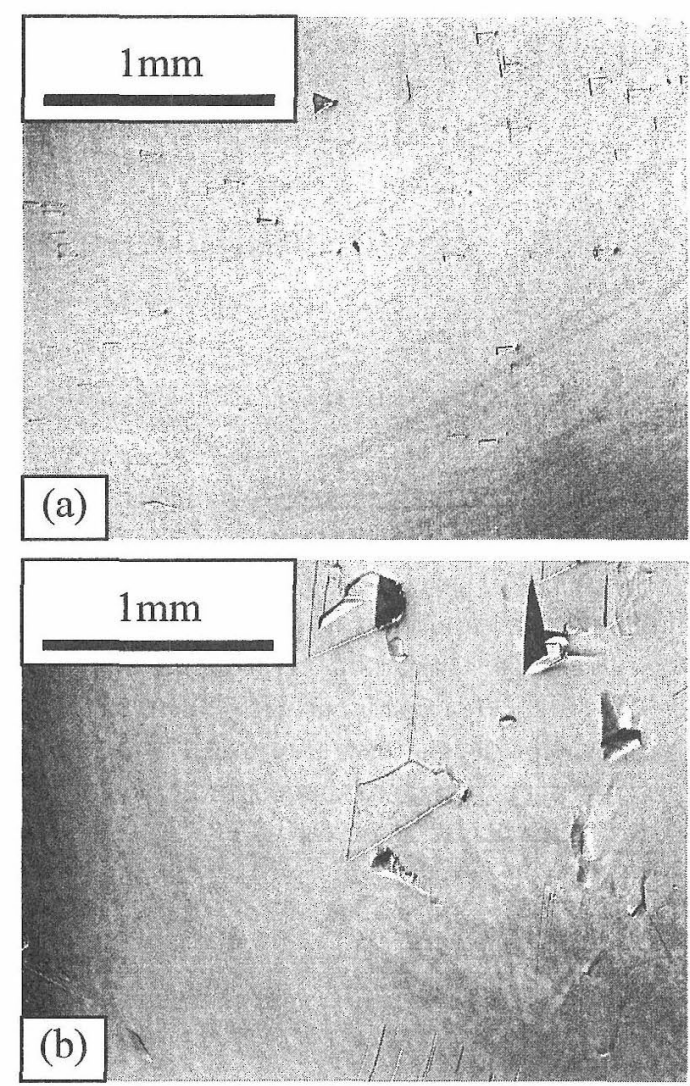

Fig. 1. Typical surface morphology of $4 \mathrm{H}-\mathrm{SiC}(0001)_{\mathrm{Si}}$ epilayers with (a) $3.5^{\circ}$ and (b) $0.2^{\circ}$ of off angles. The $\mathrm{C} / \mathrm{Si}$ ratio for the growth is 1.6 and the epilayer thickness is $5 \mu \mathrm{m}$.

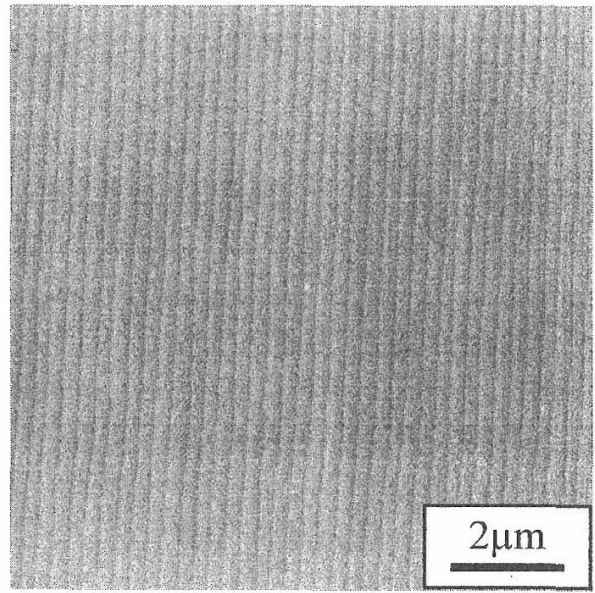

Fig. 2. Surface steps formed on a $4 \mathrm{H}-\mathrm{SiC}$ homoepitaxial layer. The substrate is $0.2^{\circ}$-off $4 \mathrm{H}-\mathrm{SiC}(0001)_{\mathrm{Si}}$. Each straight line corresponds to a step with four-bilayer height $(1.08 \mathrm{~nm})$. The grayscale is $10 \mathrm{~nm}$. Roundy objects are due to dust particles.

場合，実用上，このような表面欠陷の数を今後さらに低 減する必要がある。

Table Iに, オフ角, C/Si 比扎よび表面再研磨の有無 と主要表面欠㫟密度の関係を示す。ここで, 主要表面欠

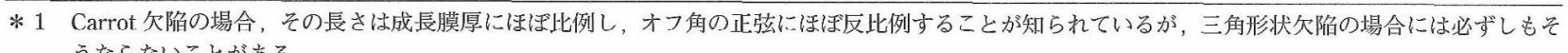
うならないことがある。 
陷密度として, carrot 欠陥と三角形状欠樎の和をとった。 この理由については後述する。オフ解によらず, C/Si 比 を 2 から 1.6 にドることで, 主要表面欠䧂密度を低減 できた。特に， 3.5 度オフおよび 0.2 度オフの場合には， 主要表面欠陷密度を約 1 枌低減できた。これは，C/Si 比 を下げることでステップフロー成長が促進される17)こと によると考えられる。これとは別に，オフ角によらず， 基板の再研磨によっても主要表面欠㫟密度を約半分に低 減できた。このことは，主要表面欠陷密度が基板表面の 状熊に依存することを示している。Table Iの結果たけ からは, 再研磨によって研磨傷が除去され, 表面平坦性 が向上したことによって, 主要表面欠陷密度が低減され たようにも見える。しかし，研磨傷の密度に比べて主要 表面欠陷密度が極端に小さいこと，扣よび，次章に見る ように，研磨傷を含も表面層を除去した後にも，研磨ダ メージは残って扣り, 主要表面欠陷が発生していること から，研磨傷自体は主要表面欠陷の発生には影響が小さ いと考觉られる。したがって, 適切な基板再研磨によっ て表面ダメージが緩和され，主要表面欠㫟密度を低減で きたと考えられる。

次に, 1 回の成長の途中で $\mathrm{C} / \mathrm{Si}$ 比を変化させた場合の 表面モフォロジーを Fig. 3 に示す。基板は 3.5 度オフで ある. C/Si 比 1.6 で成長を開始し，1.5 時間後に C/Si 此

Table I. Typical number of major surface defects (carrots plus extending triangles) on homoepitaxial layers on $4 \mathrm{H}-\mathrm{SiC}(0001)_{\mathrm{Si}}$.

\begin{tabular}{|c|c|c|c|}
\hline \multicolumn{4}{|c|}{ Number of surface defects $/ \mathrm{cm}^{-2}$} \\
\hline \multirow{2}{*}{ Supplier } & \multirow{2}{*}{ Off angle } & \multicolumn{3}{|c|}{$\mathrm{C} / \mathrm{Si}$} \\
\cline { 3 - 4 } & & 1.6 & 2 \\
\hline A & \multirow{2}{*}{$8^{\circ}$} & 2 & 5 \\
\cline { 3 - 4 } A+R & & $<1$ & 1 \\
\hline A & \multirow{2}{*}{$3.5^{\circ}$} & - & 5000 \\
\hline A+R & & 200 & 2000 \\
\hline B & $0.2^{\circ}$ & 150 & $>1000$ \\
\hline
\end{tabular}

$+\mathrm{R}$ : re-polished samples

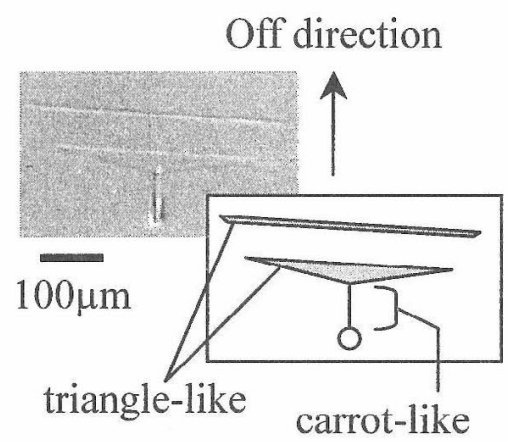

Fig. 3. Conversion of a carrot defect to an extending triangle defect during CVD growth. The substrate is $3.5^{\circ}$-off $4 \mathrm{H}-\mathrm{SiC}(0001)_{\mathrm{Si}}$. The defect behaves like a carrot under a low $\mathrm{C} / \mathrm{Si}$ ratio of 1.6 while it extends like an extending triangle defect under higher C/Si ratios of 4 and 6 .
を 6 に增加させて 50 分間成長を行い, 罙の後 C/Si 比を 1.6 に厉して 2 时間成長し, 最後に C/Si 比を 4 として 10 分間成長を行った。成長開始時には carrot 欠陥であった ものが, C/Si 比を 6 に増加した時点から横方向に広がり はじめ, 三角形状欠陥のような形状となった。しかし， C/Si 比を 1.6 に戻すと, 横方向への広がりはなくなった。 これは, carrot欠陷（オフの下流方向へ線状に伸びる） の挙動と似ている。最後にC/Si 比を 4 とすると, この 欠陷は再び横方向に広がり始めた（成長時間が短いので， Fig. 3 では横 1 本の線に見える).このことは, carrot欠 陥と三角形状欠樎は同じ起源から発生し，才フ角および 成長条件によっていずれの挙動を示すかが決まることを 示している. 8 度オフの場合には C/Si 比が高い場合にも carrot 欠陷が大多数で三角形状欠陥はほとんじ見られず, 逆に 0.2 度オフの場合には C/Si 比にかかわらず三角形状 欠陷のみで carrot 欠陥が見られないことから，オフ角が 大きい場合および C/Si 比が低い場合には carrot 的で線 状に広がるのに対し，オフ角が小さい場合または C/Si 比 が高い場合には三解形状に広がるとい气る。

Carrot欠陌の起源については，基板の螺旋転位に起因

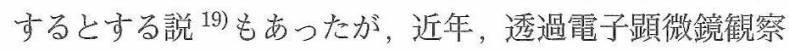
により基板表面にのみ存在する何らかの久骝に起因する との報告もあり ${ }^{20)}$ 本研究での結果と合わせると, 研磨ダ メージによりこの carrot/三角形状欠陷を発生させる何ら かの欠陷が基板表自に発生していると考えられる。

\section{$3(0001)_{C}$ 近傍面へのホモエピタキシャル成長}

\section{$3 \cdot 1$ 実験}

本章の垁験には, シクスオン社製 0.7 度オフ $4 \mathrm{H}-\mathrm{SiC}$ $(000 \overline{1})$ C 面を基板として用いた。この基板は鏡面研磨し てあるが，エピタキシャル成長用に特に研磨されたもの (epi-ready 品)ではない。本章の実験では，エピタキシャ ル成長の前に基板を $1100 \sim 1150^{\circ} \mathrm{C}$ のドライ雲囲気で熱 酸化した。熱酸化時間を変えることにより，最大で約 $0.6 \mu \mathrm{m}$ の熱酸化膜を形成した。酸化膜厚はエリプソメト リにより測定した。熱酸化による $\mathrm{SiC} の$ 除去量について 詳細な研究はなされていないが, Si の熱酸化の類推から, 熱酸化膜の厚さの約半分と一般に考学られている。

エピタキシャル成長には，前章と同じ常压横型コール ドウォール CVD 成長装置 ${ }^{13)}$ を用いた。本章における実 験では, 成長条件および成長プロセスは次のように固定 した。原料ガスは $\mathrm{SiH}_{4}$ （流量 $0.50 \mathrm{sccm}$ ）と $\mathrm{C}_{3} \mathrm{H}_{8}$ （流量 $0.33 \mathrm{sccm}$ ）であり，キャリアガスは $\mathrm{H}_{2}$ (流量 $3 \mathrm{~s} 1 \mathrm{~m}$ ）であ

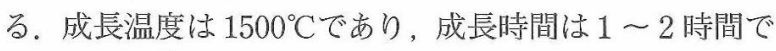
ある。この条件において, 成長速度は $3 \mu \mathrm{m} / \mathrm{h}$ 程度であ る。成長プロセスは前章と同様である。この成長前プロ セスに拈けるエッチングによる $\mathrm{SiC}$ の除去量は $0.1 \mu \mathrm{m}$ 以 下であるので, $\mathrm{SiC}$ 基板表面の除去は主に熱酸化による ものと考えられる。

\section{$3 \cdot 2$ 結果と討論}

Fig. 4 に， 0.7 度オフ $4 \mathrm{H}-\mathrm{SiC}(000 \overline{1})_{\mathrm{C}}$ 面成長層の代表 的な表面モフォロジーを示す。成長層の膜厚は約 $6 \mu \mathrm{m}$ で ある。近年の基板研磨技術の向上および成長プロセスの 

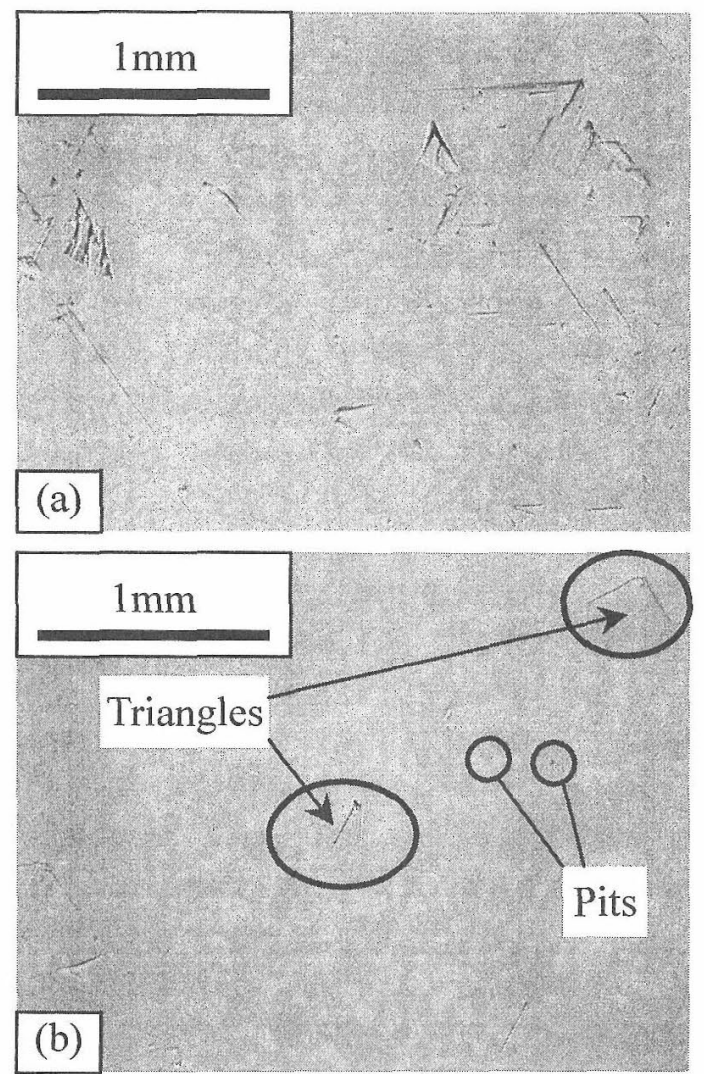

Fig. 4. Typical surface morphology of $4 \mathrm{H}-\mathrm{SiC}(000 \overline{1})_{\mathrm{C}}$ epilayers (a) without and (b) with pre-growth sacrificial oxidation.

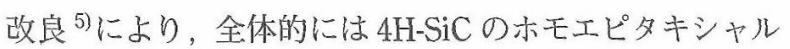
成長が実現している。主要な表面欠陥は，Fig.4 (b) に 示すような三角形状欠陥 (extending triangles) とピット (pits) である。ピットは成長膜厚が增加しても大きさは ほとんざ変わらないが，三角形状欠樎は成長膜厚にほぽ 比例して拡大する。成長前熱酸化により, これらの表面 欠陷密度は明らかに減少している。

Fig. 5 に, 成長前熱酸化膜归と表面欠陌密度の関係を 示す。いず机の表面欠陥密度も, 成長前熱酸化膜厚が $0.1 \mu \mathrm{m}$ 弱から $0.2 \mu \mathrm{m}$ にかけて急激に減少し, 吕の後は飽 和傾向となる. 成長前熱酸化膜厚が $0.4 \sim 0.5 \mu \mathrm{m}$ を超觉

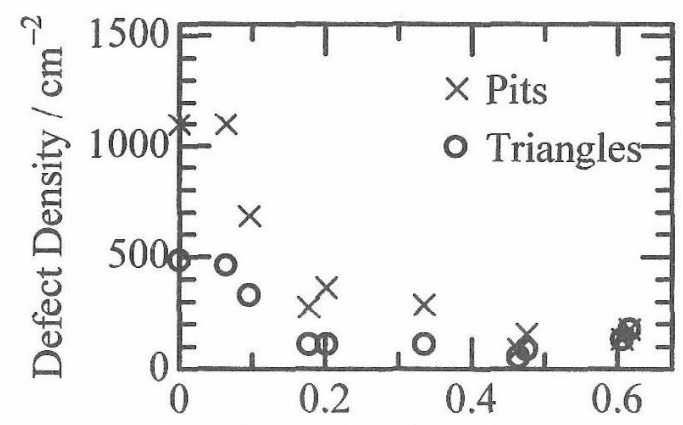

Sacrificial Oxide Thickness / $\mu \mathrm{m}$

Fig. 5. Relationship between pre-growth sacrificial oxide thickness and densities of major surface defects, pits $(x)$ and extending triangles $(\bigcirc)$, after CVD growth.
ると，表面欠陷密度が次第に增加する傾向が見られる。 成長前熱酸化膜厚が $0.2 \mu \mathrm{m}$ 以下の領域で表面欠陥密 度が減少するのは，基板作製時の研磨ダメージ4),5)がこ の上うな深さ方向分布をとっているためと考学られる。 受領直後の基板をAFMにより観察すると，Fig. 6 に示 すように深さ数 $\mathrm{nm}$ の研磨傷が無数に観測されるが，実 際の研磨がメージはさらに深く, 約 $0.1 \mu \mathrm{m}$ 程度まで分布 していると考光られる。

Fig. 5 に批いて, 成長前熱酸化膜厚が $0.4 \mu \mathrm{m}$ より大き い領域で表面欠宿密度が次第に増加するのは, 熱酸化後 の冷却時に, 蓺膨張係数の違いに起因して $\mathrm{SiC}$ 表面が熱 酸化膜から受ける応力が, 熱酸化膜厚の増大とともに増 大することに起因すると考光られる。筆者らは既に， $(0001)_{\mathrm{Si}}$ 面に㧤いてはわずかの熟酸化によっても表面欠 陷密度が增加すること5)を報告しているが，(0001) c面で は応力の緩和が㧍号らく容易であるために，酸化膜厚が $0.4 \sim 0.5 \mu \mathrm{m}$ 程度までは応力の影響を南まり受けないと 推測される。

なお，近年， $4 \mathrm{H}-\mathrm{SiC}(000 \overline{1})_{\mathrm{C}}$ 近傍面において，2 イン

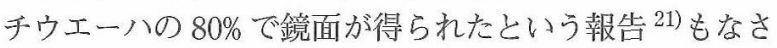

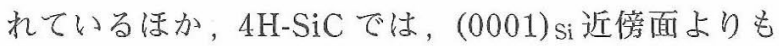
$(000 \overline{1})_{C}$ 近傍面のほうが 3C-SiC の混入が少ないという報 告もある。 $\left.{ }^{22}\right)$ オフ面では $(000 \overline{1})$ C 面の方が表面平坦性に優 れていた9ことを考元ると， $4 \mathrm{H}-\mathrm{SiC}\{0001\}$ 近傍面への ホモエピタキシャル成長には， $(000 \overline{1})_{\mathrm{C}}$ 面の方が有望で 莗らう。

\section{4 結言}

$4 \mathrm{H}-\mathrm{SiC}(0001)_{\mathrm{Si}}$ 低オフ角面へのホモエピタキシャル成 長に打いて，基板再研磨抢よび CVD 成長時の C/Si 比が 成長層の表面欠宿密度に及ぼす影響を調べた。低才フ角 面に打いて，基板再研磨は表面欠陷密度を約半分に低減 する効果があったことから, 表面欠陷の多くは基板最表 面の研磨ダメージから発生するものと教えられる。さら に，C/Si 比を従来の 2 から 1.6 まで下げることで, 表面

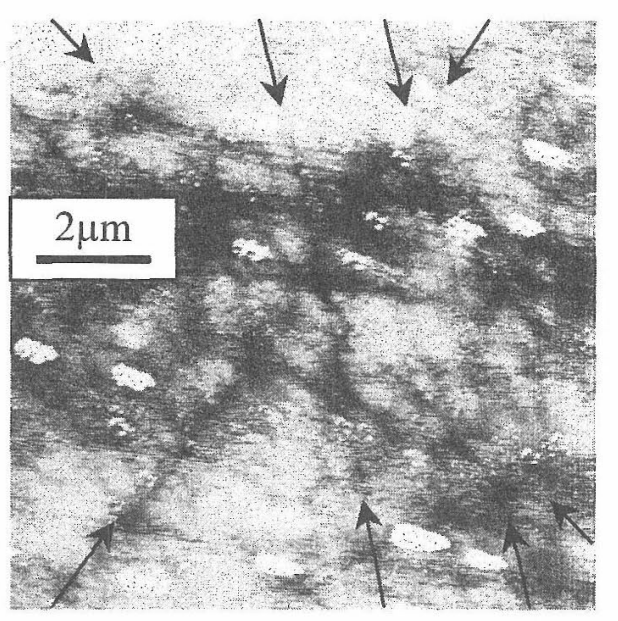

Fig. 6. Typical AFM image of an as-received SiC substrate used in this study. Arrows indicate some of scratches. The grayscale is $10 \mathrm{~nm}$. Roundy objects are due to dust particles. 
欠陥密度は約 1 桁低減でき, 3.5 度オフおよび 0.2 度オフ 基板に拈いて, $150 \sim 200 \mathrm{~cm}^{-2}$ となった。しかし， 0.2 度 オフの場合は，オフ角が極端に小さいことに起因して 個々の表面欠陥が数 $100 \mu \mathrm{m}$ 以上にわたって広がるため, この表面欠陥密度では実用上まだ不十分であり, 研磨ダ メージを完全に除去する技術の早急な確立が望まれる.

$4 \mathrm{H}-\mathrm{SiC}(000 \overline{1})_{\mathrm{C}} 0.7$ 度オフ面へのホモエピタキシャル 成長において, 成長前熱酸化が CVD 成長後の表面欠陷密 度に及ぼす影響を調べた，表面欠陷密度は，熱酸化膜厚 が $0.1 \mu \mathrm{m}$ 弱から $0.2 \mu \mathrm{m}$ にかけて急激に減少し, その後, 熱酸化膜厚が $0.4 \sim 0.5 \mu \mathrm{m}$ までは飽和傾向を示した. 熱 酸化膜厚が $0.5 \mu \mathrm{m}$ 以上になると, 表面欠陥密度は次第に 増加する傾向が見られた。熱酸化膜が薄い領域で熱酸化 膜厚とともに表面欠陷密度が減少するのは, 研磨ダメ一 ジの深さ方向分布によるものと考えられる.オフ角の小 さい $\mathrm{SiC}(000 \overline{1})_{\mathrm{C}}$ 面上へのホモエピタキシャル成長に扎い ては, 適切な熱酸化により研磨ダメージを除去すること が有効である。

付言するに，現在主に研究が進められている $(0001)_{\mathrm{Si}}$ 面では熱酸化が有効ではない.5) $(0001)_{\mathrm{Si}}$ 面に対しては研 磨技術の向上により表面欠陥を発生させる研磨ダメージ を除去することが必要である.

本研究は, 文部科学省の地域科学技術振興補助金（知 的クラスター事業補助金) および 21 世紀 COE プロジェ クトの支援を受けて行われた。

\section{参 考 文 献}

1）松波弘之, “半導体 $\mathrm{SiC}$ 技術と応用”（2003）日刊工業新 聞社.

2）荒井和雄, 吉田貞史, “SiC 素子の基礎と応用”（2003）オ一 么社.

$3)$ N. Kuroda, K. Shibahara, W. S. Yoo, S. Nishino and H. Matsunami, Ext. Abstr. $19^{\text {th }}$ Conf. on Solid State Devices and Materials, 227 (1987).

4) J. A. Powell, J. B. Petit, J. H. Edgar, I. G. Jenkins, L. G. Matus, J. W. Wang, P. Pirouz, W. J. Choyke, L. Clemen and M. Yoganathan, Appl. Phys. Lett., 59, 333 (1991).
$5)$ S. Nakamura, T. Kimoto and H. Matsunami, J. Cryst. Growth, 256, 341 (2003).

$6)$ J. A. Powell, P. G. Neudeck, A. J. Trunek, G. M. Beheim, L. G. Matus, R. W. Hoffmann, Jr. and L. J. Keys, Appl. Phys. Lett., 77, 1449 (2000).

7) T. Kimoto and H. Matsunami, J. Appl. Phys., 78, 3132 (1995).

$8)$ H. S. Kong, J. T. Glass and R. F. Davis, J. Appl. Phys., 64, 2672 (1988).

9) T. Kimoto, A. Itoh and H. Matsunami, Appl. Phys. Lett., 66, 3645 (1995).

10) K. Fukuda, M. Kato, K. Kojima and J. Senzaki, Appl. Phys. Lett., 84, 2088 (2004).

11) N. Tokura, K. Hara, Y. Takeuchi, T. Miyajima and K. Hara, Inst. Conf. Ser., 142, 637 (1996).

12) K. Ueno, phys. stat. sol. (a), 162, 299 (1997).

13) H. Matsunami, K. Shibahara, N. Kuroda, W. S. Yoo and S. Nishino, Springer Proc. in Physics, 34, 34 (1989).

14) T. Kimoto, H. Nishino, W. S. Yoo and H. Matsunami, J. Appl. Phys., 73, 726 (1993).

15) S. Nakamura, T. Kimoto, H. Matsunami, S. Tanaka, N. Teraguchi and A. Suzuki, Appl. Phys. Lett., 76, 3412 (2000).

16) S. Nakamura, T. Kimoto and H. Matsunami, Mater. Sci. Forum, 389-393, 183 (2002).

17) T. Kimoto and H. Matsunami, Appl. Phys. Lett., 66, 3645 (1995).

18) S. Nakamura, T. Kimoto and H. Matsunami, Jpn. J. Appl. Phys., 42, L846 (2003).

19) I. Kamata, H. Tsuchida, T. Jikimoto and K. Izumi, Mater. Sci. Forum, 353-356, 311 (2001).

20) T. Okada, T. Kimoto, K. Yamai, H. Matsunami and F. Inoko, Mater. Sci. \& Eng., A361, 67 (2003).

21）児島一聡, 黒田悟史, 石田夕起, 高橋徹夫, 奥村 元, 荒井和雄, 第 64 回応用物理学会学術講演会講演予稿集, 1a-B-2 (2003).

22) C. Hallin, Q. Wahab, I. Ivanov, P. Bergman and E. Janzén, Mater. Sci. Forum, 457-460, 193 (2004). 